Schwerpunkt

Herzschr Elektrophys 2020 • 31:273-287

https://doi.org/10.1007/s00399-020-00710-x

Received: 3 July 2020

Accepted: 8 July 2020

Published online: 7 August 2020

(c) Springer Medizin Verlag $\mathrm{GmbH}$, ein Teil von Springer Nature 2020

\section{Introduction}

Cardiac implantable electronic devices (CIEDs) are a cornerstone of arrhythmia and heart failure detection as well as management. Pacemakers and implantable cardioverter/defibrillators (ICDs) are extending and improving lives for millions, with continuously improved algorithms to enhance detection and the delivery of therapy. In recent years the "implantable" part of the CIED acronym has started to lose importance as new kinds of devices are emerging which can be used subcutaneously or worn on the skin. In particular for large-scale monitoring for arrhythmias, small, unobtrusive gadgets seem positioned to upend paradigms with a potentially profound impact on care delivery.

The clinical performance of CIEDs is only as good as their sensing and detection capacities. Sensing is defined as the process for identifying the electrical signals that indicate atrial or ventricular depolarisation events. Detection refers to the analysis and classification of sensed signals by advanced device algorithms to determine the cardiac rhythm. Thus detection follows sensing [65]. Whether for pacing, defibrillation or diagnostic monitoring of arrhythmias, the device must be able to process and filter the sensed signal to reduce noise and to exclude irrelevant physiological signals.

"We see only what we know", Johann Wolfgang von Goethe remarked over 200 years ago. The pitfalls of over- and undersensing of electric potentials with cardiac

Johannes Sperzel · Christian W. Hamm • Andreas Hain

Heartcenter, Electrophysiology/Device therapies, Kerckhoff-Klinik GmbH, Bad Nauheim, Germany

\title{
Over- and undersensing-pitfalls of arrhythmia detection with implantable devices and wearables
}

devices reflect their lack of "knowledge" of arrhythmia detection. Instead, they must rely on algorithms of varying sensitivity. The sensing method, whether using endocardial leads, subcutaneous/ skin electrodes or analysis of digital pulse waveforms, will influence the quality of the signal received by the device. Further, the source of a sensed signal needs to be established: is it atrial or ventricular, an R-wave or a T-wave, ventricular or supraventricular extrasystole, a muscle potential or from an external electric field? - Figs. 1 and 2 illustrate some of these considerations.

The demands on sensing and detection quality will differ depending on how the information is applied. With a pacemaker or ICD, withheld or erroneous therapy can have severe consequences and accurate and reliable detection of cardiac function is crucial. Monitoring devices are usually used in risk assessment and management, with greater tolerance for isolated artefacts or lower quality of readings.

Three sensing methods are currently in use with cardiac monitoring devices (- Table 1). Implantable devices with leads attached to cardiac tissue use direct intrinsic sensing. For electrical activity to be transmitted from the heart to the device, a closed electrical circuit must be present. With pacemakers and ICDs, modern leads are generally bipolar, allowing signals to be detected between lead tip and ring electrodes. The alternative is unipolar sensing, which detects electrical activity occurring between the tip of the lead and the pulse generator. As the distance between lead tip and device represents a large dipole, unipolar sensing is much more prone to external interference [54].

Subcutaneous ICDs (s-ICDs) and insertable cardiac monitors (ICMs) record far-field subcutaneous electrograms obtained by sensing from a subcutaneous electrode to the can (S-ICD) or between subcutaneous electrodes on the device itself (ICM). Wearable defibrillators employ sensors placed directly on the skin of the patient. Finally, the growing number of wearable devices capable of monitoring rely on indirect measurements by photoplethysmography (PPG; digital pulse waveforms) and refine their algorithms by the use of Big Data and artificial intelligence (AI) to compensate for weaknesses in the sensing technology itself.

\section{Pacemakers}

Pacemakers rely on intracardiac electrograms for cardiac rhythm monitoring. Accurate sensing is important to deliver appropriate therapy, including minimising the amount of ventricular pacing to avoid long-term risk for complications [62], and to achieve a high percentage of biventricular pacing with resynchronisation devices [35]. Pacemakers can also be programmed to detect atrial high rate episodes (AHRE) and identify atrial fibrillation (AF) or other tachyarrhythmias (- Figs. 3 and 4).

A unique approach has been developed for leadless pacemakers (which are 


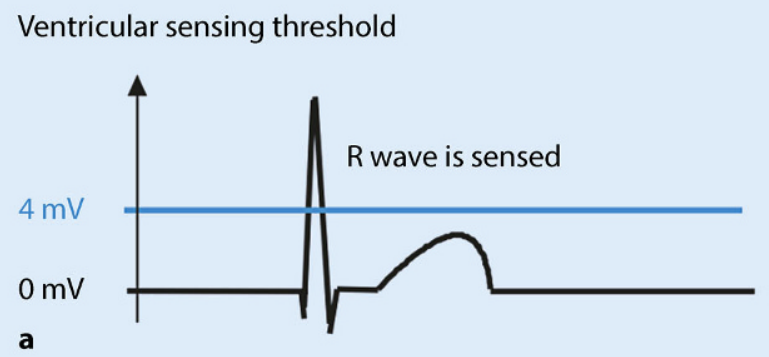

Ventricular sensing threshold

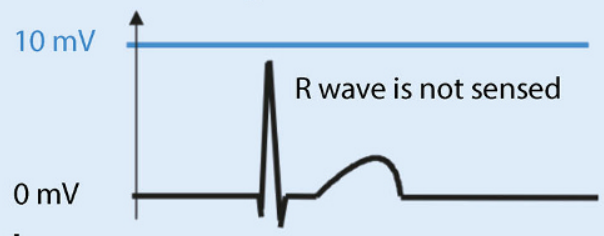

b

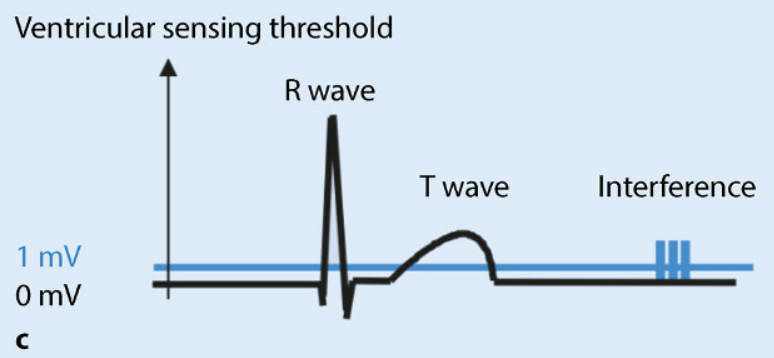

Fig. $1<$ aSchematic illustration of an electrogram with sensing threshold and sensed $R$ wave. b Example of overly high sensing threshold and resulting undersensing of a true $\mathrm{R}$ wave. $\mathrm{CEx}$ ample of overly low sensing threshold and resulting oversensing of noise. All images in 0 Figs. 1 and 2 are from Morschhäuser et al. [42] and reproduced with kind permission from the publisher

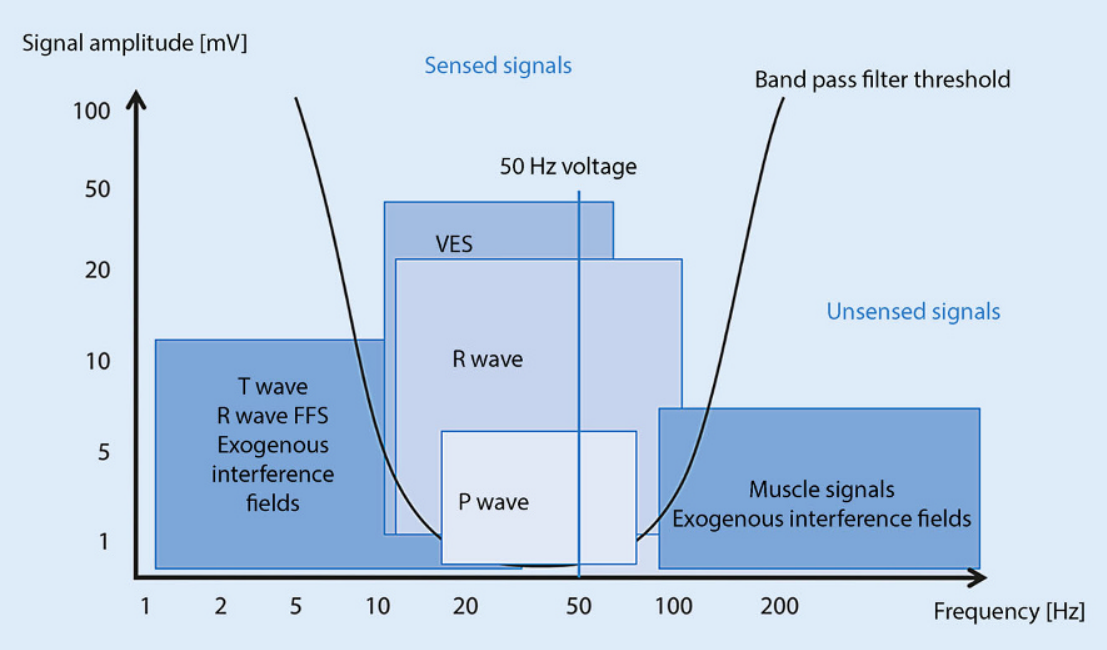

Fig. $2 \Delta$ Band pass filters for pacemakers. VES Ventricular Extrasystole

single-chamber devices). The algorithm uses information from a three-axis accelerometer in the device to sense atrial contraction and switches pacing mode according to the presence or absence of atrioventricular $(\mathrm{AV})$ conduction, as well as high patient activity [15]. The method has been used successfully to provide AV synchronous pacing in patients with persistent complete AV block and normal sinus rhythm [61].

Dual-chamber pacemakers have the advantage over single-chamber devices of providing direct atrial sensing in addition to ventricular sensing. The disadvantage is the need for an additional lead. There is also a risk of oversensing. Dual-chamber pacemakers may interpret a ventricular depolarisation signal received by the atrial channel as a $P$ wave, a phenomenon known as far-field $\mathrm{R}$-wave oversensing. This is more likely to occur in cases of atrial unipolar sensing, ventricular pacing, long bipole spacing and septal or low right atrial implants $[25,30,38,48,53]$. There is also concern that atrial pacing may be sensed by the ventricular lead.

The accuracy of arrhythmia detection can further be influenced by variables such as lead sensitivity, cut-off detection rate, cardiac tissue refractory period and unipolar vs bipolar lead configuration. The device may under-detect AF due to undersensing of the atrial electrogram, or incorrectly log a long episode as multiple short episodes [39]. Retrograde conduction may lead to pacemaker-mediated tachycardia [32], although most modern dual-chamber pacemakers include algorithms to minimise this risk. False-positive detections due to far-field R-wave oversensing of ventricular signals in the atrium can be minimised by individual adjustment of the postventricular atrial blanking period [34].

The positive predictive value (PPV) of AHREs is lower when short detection durations (less than $5 \mathrm{~min}$ ) are programmed, but even for longer episodes, the PPV for AHREs lasting between $6 \mathrm{~min}$ and $6 \mathrm{~h}$ may be only a modest $83 \%$ [32]. The PPV for AF detection has been reported as 95 and $91 \%$ for Medtronic and Biotronik devices, respectively [41]. Abbott devices report a PPV of $97 \%$ for AHRE episodes $>6 \mathrm{~h}$ [44]. For short episodes, manual adjudication may be necessary [59].

\section{Implantable cardioverter- defibrillators}

Transvenous ICDs combine pacemaker and defibrillator functions. These may rely on different electrograms. Sensing is either true bipolar (sensing between the tip and ring electrodes) or integrated bipolar (sensing between the tip and right ventricular [RV] coil electrodes integrating pace-sense and defibrillation func- 
tions) (• Fig. 5). The shock electrogram records a more global far-field signal between widely separated, high-voltage electrodes, usually the RV coil and device can. ICDs often employ an automatic sensitivity adjustment algorithm, which measures the highest amplitude peak of the signal for each sensed event and sets the sensing threshold at a programmable percentage of the peak, subsequently reducing the threshold until there is a new sensed event.

If the pace-sense functions of transvenous ICDs are similar to pacemakers, the key challenge of the devices is the correct discrimination of arrhythmias to terminate potentially lethal ventricular tachycardias while keeping the rate of inappropriate shocks to a minimum. Inappropriate shocks are painful and frightening to patients. They also increase mortality compared with no shocks [51] as well as with non-shocking methods such as antitachycardia pacing [63].

In most cases, inappropriate shocks are caused by erroneous discrimination of supraventricular tachycardia [20]. Although they lack an atrial lead, singlechamber devices are still able to detect atrial arrhythmias by close analysis of the ventricular signal. Tachycardias, whether ventricular or atrial, are characterised by changes in the morphology of the ventricular electrogram. Sinus tachycardia typically has a gradual onset and a parallel acceleration of atrial and conducted ventricular intervals, whereas ventricular tachycardia is abrupt, with at least transient AV dissociation [68]. However, inappropriate classification can happen, e.g. when an atrial tachycardia has an abrupt onset and is regular, even if the morphology is consistent with supraventricular tachycardia [24]. Also, morphology as a single discriminator has limited sensitivity for appropriate diagnosis of ventricular arrhythmias [66]. Similar to pacemakers, dual-chamber devices are associated with improved detection of AHRE as well as with fewer inappropriate shocks $[9,24]$.

A more recent development is a single-chamber system with complete atrial diagnostics. Here, atrial signals can be sensed by the atrial dipole of the RV lead (similar to a VDD pacemaker). In addi-

Herzschr Elektrophys 2020 - 31:273-287 https://doi.org/10.1007/s00399-020-00710-x

(c) Springer Medizin Verlag GmbH, ein Teil von Springer Nature 2020

\section{J. Sperzel · C. W. Hamm · A. Hain}

\section{Over- and undersensing - pitfalls of arrhythmia detection with implantable devices and wearables}

\section{Abstract}

Cardiac implantable electronic devices (CIEDs) are a cornerstone of arrhythmia and heart failure detection as well as management. In recent years new kinds of devices have emerged which can be used subcutaneously or worn on the skin. In particular for large-scale arrhythmia monitoring, small, unobtrusive gadgets seem positioned to upend paradigms and care delivery. However, the performance of CIEDs and wearables is only as good as their sensing and detection capacities. Whether for pacing, defibrillation or diagnostic monitoring, the device must be able to process and filter the sensed signal to reduce noise and to exclude irrelevant physiological signals. The demands on sensing and detection quality will differ depending on how the information is applied. With a pacemaker or implantable cardioverter/defibrillator, withheld or erroneous therapy can have severe consequences and accurate and reliable detection of cardiac function is crucial. Monitoring devices are usually used in risk assessment and management, with greater tolerance for isolated artefacts or lower quality of readings. This review discusses sensing and detection and the performance to date by CIEDs as well as subcutaneous and wearable devices.

\section{Keywords}

Over- and undersensing · Pacemaker . Defibrillator - Wearables · Arrhythmia detection

\section{Over- und Undersensing - Fallstricke der Arrhythmiedetektion mit implantierbaren Geräten und Wearables}

\section{Zusammenfassung}

Kardiale implantierbare elektronische Systeme (CIED) stellen Eckpfeiler in der Diagnostik und Therapie von Herzrhythmusstörungen und Herzinsuffizienz dar. In den letzten Jahren wurden neue Geräte entwickelt, die subkutan implantiert oder als sogenannte Wearables getragen werden können. Insbesondere im permanenten Arrhythmiemonitoring scheinen kleine, unauffällige Geräte das Potenzial zu haben, Paradigmen umzustoßen und die Versorgung zu verändern. Die Leistung von CIED und Wearables ist jedoch nur so gut wie deren Wahrnehmungs- und Detektionseigenschaften. Unabhängig von der Nutzung als Herzschrittmacher, Defibrillator oder Monitoring-Device muss durch spezielle Filter und Algorithmen sichergestellt werden, dass das wahrgenommene intrinsische Signal von Störsignalen oder irrelevanten physiologischen Signalen differenziert werden kann. Die Anforderungen an die Wahrnehmungs- und Detektionsqualität sind davon abhängig, wie die Informationen genutzt werden. Eine durch Oversensing oder Undersensing zurückgehaltene oder falsche Therapie bei Patienten mit Herzschrittmacher oder implantierbarem Kardioverter/Defibrillator kann zu schweren Komplikationen führen, weshalb eine genaue und verlässliche Detektion der Herzfunktion hier kritisch ist. Systeme zum alleinigen Monitoring finden vor allem in der Risikoabschätzung und Therapieoptimierung Verwendung, wobei vereinzelte Artefakte oder eine geringere Messqualität hier tolerabler sind. Die vorliegende Übersicht beschreibt die Wahrnehmungs- und Detektionsfunktion sowie die resultierende Qualität der verfügbaren CIED, subkutanen Systeme und Wearables.

\section{Schlüsselwörter}

Over- und Undersensing · Herzschrittmacher . Implantierter Defibrillator/Cardioverter . Wearables · Arrhythmiedetektion tion to the detection of atrial fibrillation, the advantage is improved discrimination between atrial and ventricular tachyarrhythmias.

Oversensing, often of $\mathrm{T}$ waves, makes a relevant contribution to inappropriate shocks. In earlier generations of defibrillators, T-wave oversensing was responsible for around $14 \%$ of inappropriate shocks [67], but improved algorithms have reduced the risk to less than $5 \%$ [4]. In contrast to the static programmed 


\section{Schwerpunkt}

\begin{tabular}{|c|c|c|c|c|c|}
\hline System & Sensing method & Sensing vectors & VA sensing & AA sensing & Implantation \\
\hline $\begin{array}{l}\text { Single-chamber } \\
\text { pacemaker/ICD }\end{array}$ & $\begin{array}{l}\text { Intrinsic in RA } \\
\text { and/or RV }\end{array}$ & & $\begin{array}{l}\text { Direct by atrial } \\
\text { or ventricular } \\
\text { electrode }\end{array}$ & $\begin{array}{l}\text { Indirect through } \\
\text { analysis of } \\
\text { ventricular } \\
\text { signals }\end{array}$ & $\begin{array}{l}\text { Invasive: } \\
\text { device + lead }\end{array}$ \\
\hline $\begin{array}{l}\text { Dual-chamber pace- } \\
\text { maker/ICD/CRT }\end{array}$ & $\begin{array}{l}\text { Intrinsic in RA and } \\
\mathrm{RV}\end{array}$ & & $\begin{array}{l}\text { Direct by atrial } \\
\text { and/or ventricu- } \\
\text { lar electrode }\end{array}$ & $\begin{array}{l}\text { Direct by atrial } \\
\text { electrode }\end{array}$ & $\begin{array}{l}\text { Invasive: } \\
\text { device + up to } \\
\text { three leads }\end{array}$ \\
\hline$S-I C D$ & $\begin{array}{l}\text { Far-field subcuta- } \\
\text { neous electrograms }\end{array}$ & & $\begin{array}{l}\text { Direct by sub- } \\
\text { cutaneous } \\
\text { electrode and } \\
\text { can }\end{array}$ & $\begin{array}{l}\text { Indirect through } \\
\text { analysis of } \\
\text { ventricular } \\
\text { signals }\end{array}$ & $\begin{array}{l}\text { Invasive: } \\
\text { device + lead }\end{array}$ \\
\hline ICM & $\begin{array}{l}\text { Far-field subcuta- } \\
\text { neous electrograms }\end{array}$ & & $\begin{array}{l}\text { Direct by sub- } \\
\text { cutaneous } \\
\text { electrodes on } \\
\text { device }\end{array}$ & $\begin{array}{l}\text { Indirect through } \\
\text { analysis of } \\
\text { ventricular } \\
\text { signals }\end{array}$ & $\begin{array}{l}\text { Minimally inva- } \\
\text { sive: } \\
\text { device }\end{array}$ \\
\hline
\end{tabular}

sensing of pacemakers, ICDs have established algorithms with dynamic adjustment of sensing parameters.

\section{Pitfalls in sensing - between oversensing and undersensing}

Case Study: Reduced RV Sensing after ICD Upgrade. An ICD system changeover, including a change of the pulse generator, was carried out in a patient born in 1947. The RV lead provided good measurements during surgery (RV sensing $8.5 \mathrm{mV}$, capture threshold1V@0.5 ms). However, after surgery, the average RV sensing was about $4.2 \mathrm{mV}$. Potential damage to the lead during surgery was considered to be the reason, but the capture threshold was stable. Other causes for the reduced RV sensing needed to be found.

It turned out that the low frequency attenuation (LFA) filter in the new device was switched off. The LFA filter was designed to help mitigate $\mathrm{T}$-wave oversensing. When the filter is programmed on, it attenuates, or reduces, the ampli- 


\begin{tabular}{|c|c|c|c|c|c|}
\hline System & Sensing method & Sensing vectors & VA sensing & AA sensing & Implantation \\
\hline $\begin{array}{l}\text { Wearable } \\
\text { defibrillator }\end{array}$ & Sensors on skin & & $\begin{array}{l}\text { Direct by sen- } \\
\text { sors on skin }\end{array}$ & $\begin{array}{l}\text { Indirect through } \\
\text { analysis of } \\
\text { ventricular } \\
\text { signals }\end{array}$ & Non-invasive \\
\hline Wearables & $\begin{array}{l}\text { Indirect mea- } \\
\text { surements (pho- } \\
\text { toplethysmo- } \\
\text { graphy) }\end{array}$ & 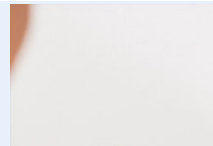 & $\begin{array}{l}\text { Indirect mea- } \\
\text { surements }\end{array}$ & $\begin{array}{l}\text { Indirect through } \\
\text { analysis of } \\
\text { ventricular } \\
\text { signals }\end{array}$ & Non-invasive \\
\hline
\end{tabular}

tude oflow-frequency signals. As a result, there is a significant reduction in T-wave oversensing (• Fig. 6a,b).

In the authors' patient, the deactivated LFA filter resulted in reduced RV sensing. Activating the filter led to acceptable RV sensing with no need for RV lead revision (• Fig. 7a,b).

\section{Subcutaneous ICDs}

The S-ICD is placed as an alternative to transvenous ICD when there are concerns about risk of vascular occlusion, systemic infection or adverse effects of lead extraction. As they are limited by their inability to treat bradyarrhythmia or provide antitachycardia pacing, current guidelines recommend S-ICDs in patients without a pacing indication or an indication for CRT and in whom it is not expected that such indications will develop [2, 52].

In addition to these limitations, the S-IDC is associated with a greater risk of inappropriate shock therapy, particularly in patients with hypertrophic cardiomyopathy or a history of AF [43, 45, 56, 69]. Lacking a transvenous lead, the S-ICD relies on far-field electrograms (resembling a surface electrocardiogram; - Fig. 8). Algorithms discriminate supraventricular arrhythmias based on morphology and R/T ratio [27]. Compared with endocardial sensing electrograms, the far-field varietyhas lower amplitude $(0.3-4.0 \mathrm{mV})$, longer duration, lower frequency content and greater postural variation [64]. In contrast to transvenous ICDs, the driver of inappropriate shocks with S-ICDs is not erroneous supraventricular tachycardia diagnosis, where the performances are comparable [27], but oversensing, especially T-wave oversensing [37]. Higher 12-lead electrocardiographic R-wave amplitude and abnormal T-wave inversions have been reported to be independent predictors of increased risk of inappropriate shocks, whereas the presence of T-wave inversions was associated with a significantly lower risk of inappropriate shocks [43].
Inappropriate shocks may also be triggered by oversensing of low-amplitude signals related to myopotentials during exercise [1]. A systematic evaluation of consecutive S-ICD patients for myopotential inducibility in 2019 found that exercise such as isometric chest press, weight-lifting and side plank exercise could all induce myopotentials which led to undersensing in up to $66 \%$ and oversensing in up to $22 \%$ of patients [11]. S-ICD lead and generator position did not appear to affect the induction of myopotentials. In a single-centre study of S-ICD patients with 6-month follow-up, appropriate shocks caused by myopotentials were almost exclusively registered on the primary sensing vector, an association not found for shocks caused by T-wave oversensing [56].

As with transvenous ICD, algorithms that reduce the risk of T-wave oversensing are being continually refined. The latest complex algorithm was developed using a database of recorded episodes and a computer model that simulates 
1: A sensing, enhanced automatic scaling $(2.2 \mathrm{~mm} / \mathrm{mV})$ 2: $V$ sensing, enhanced automatic scaling $(1.4 \mathrm{~mm} / \mathrm{mV})$

3: Cableless ECG, automatic scaling $(1.4 \mathrm{~mm} / \mathrm{mV})$

Sweep speed: $25 \mathrm{~mm} / \mathrm{s}$

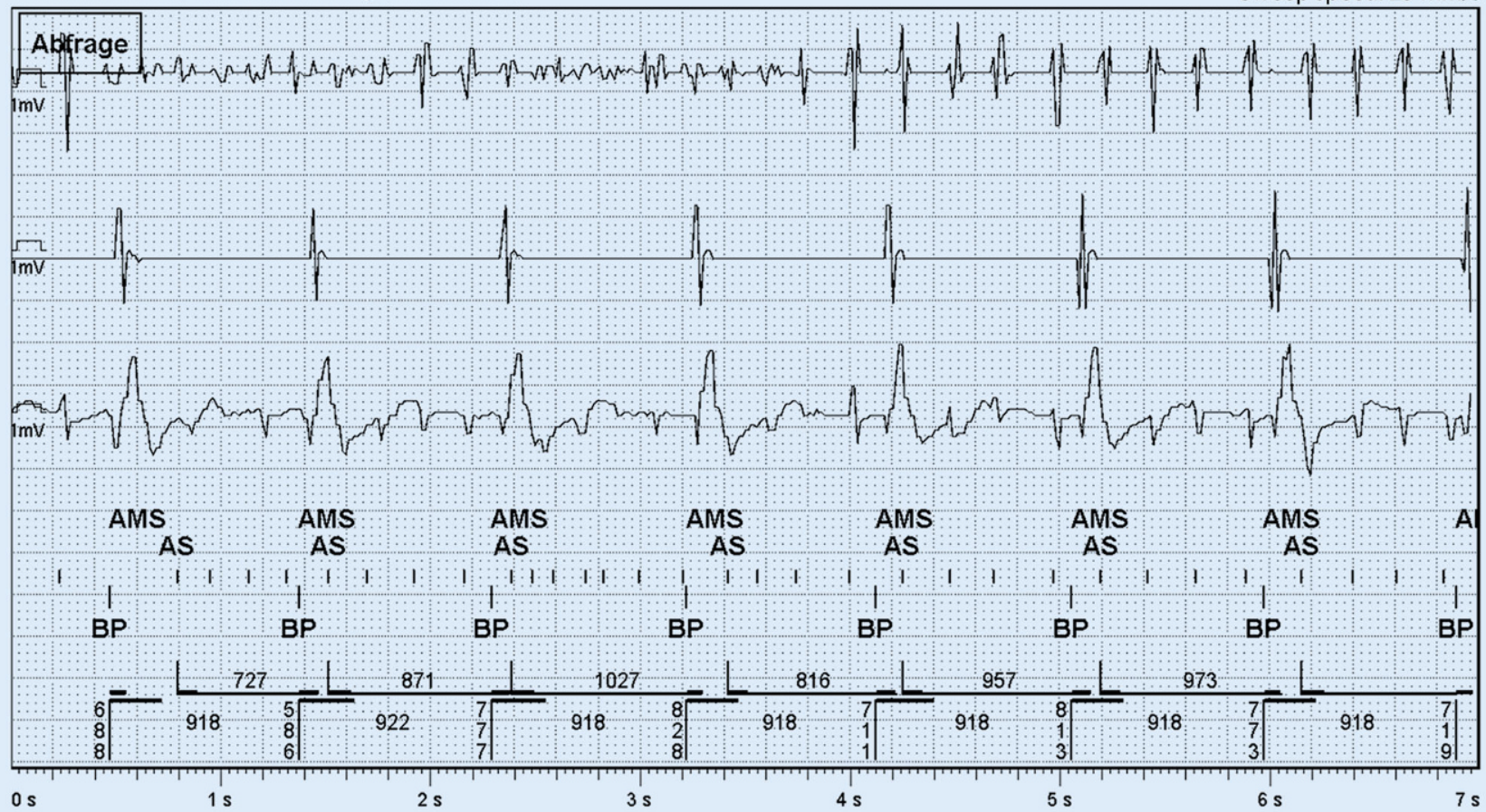

Fig. $3 \Delta$ Automatic mode switch during atrial fibrillation

1: $V$ bipolar automatic scaling $(3.0 \mathrm{~mm} / \mathrm{mV})$

2: Marker

3: $V$ sensing, enhanced automatic scaling $(1.8 \mathrm{~mm} / \mathrm{mV})$

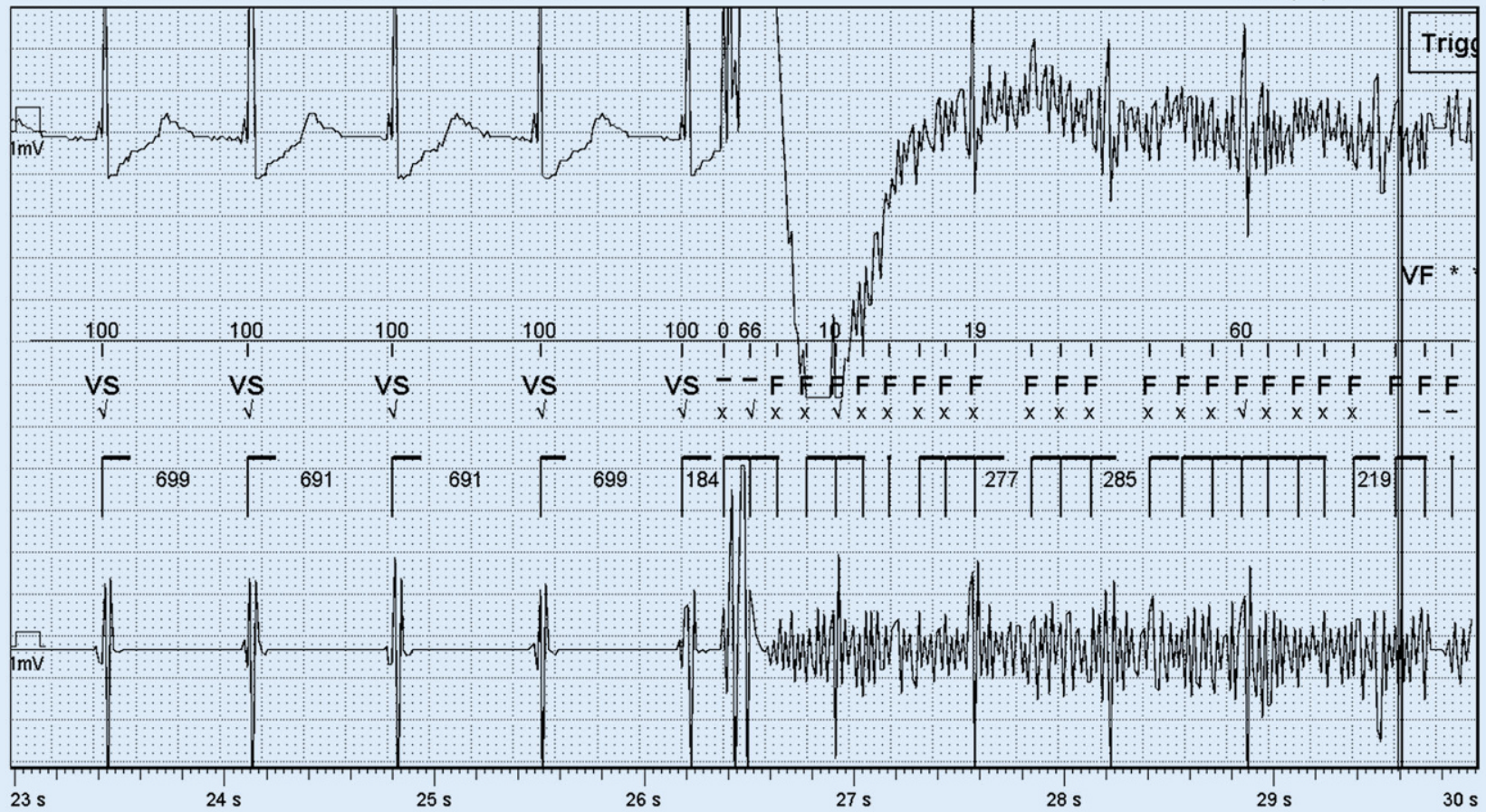

Fig. $4 \Delta$ Incorrect detection of ventricular fibrillation due to noise 

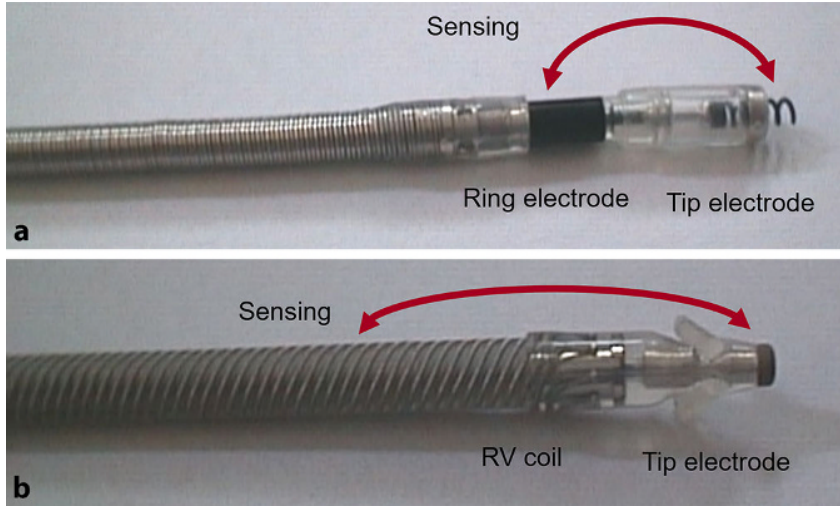

Fig. $5<$ a True

bipolar sensing;

b Integrated bipolar

sensing. $R V$ right

ventricular

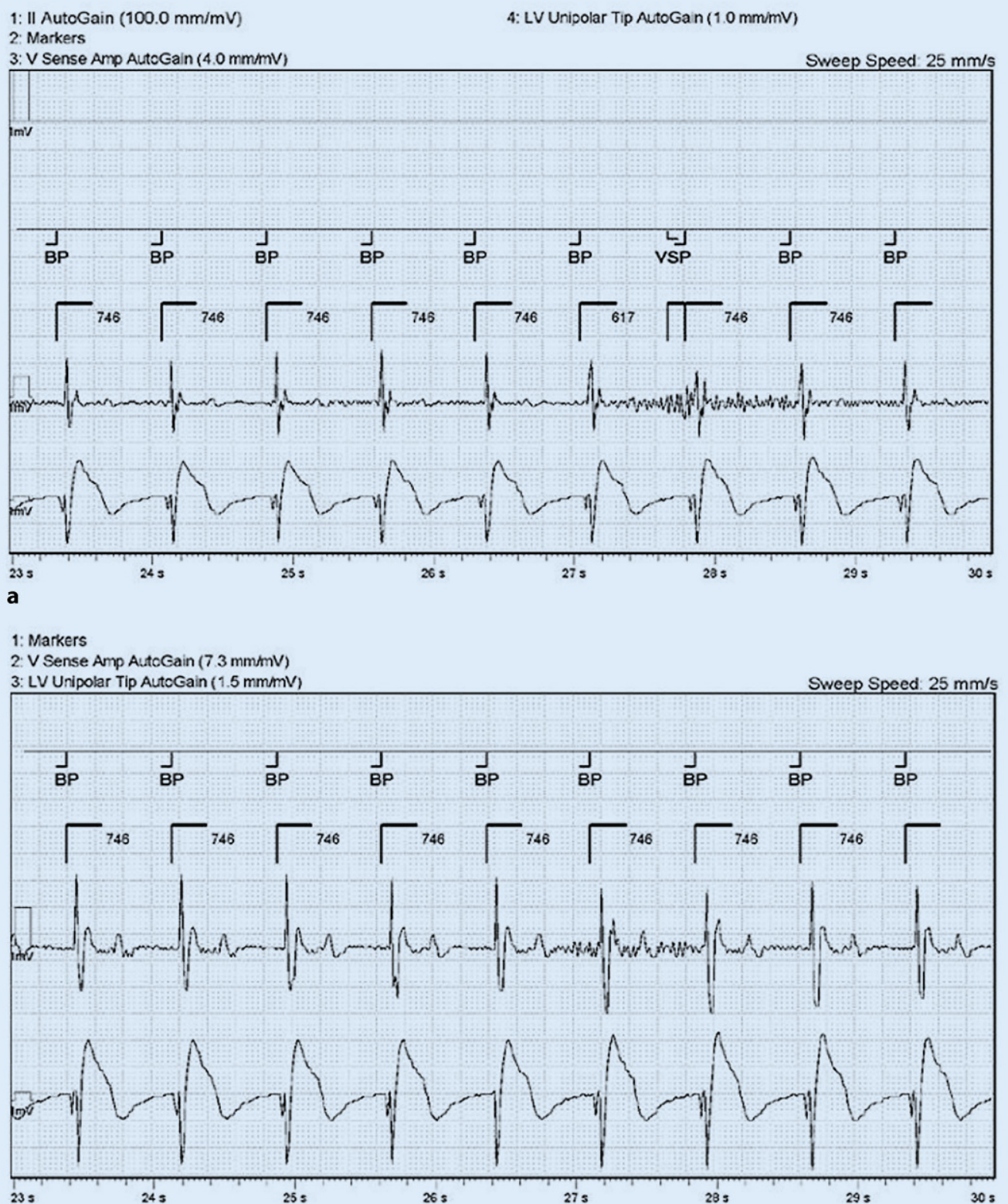

Fig. $6<$ a Myopotential signals $(\sim 0.8 \mathrm{mV})$ are oversensed with the low frequency attenuation on b Signals $(\sim 0.27 \mathrm{mV})$ are still present but not oversensed. $V$ ventricular, $L V$ left ventricular 


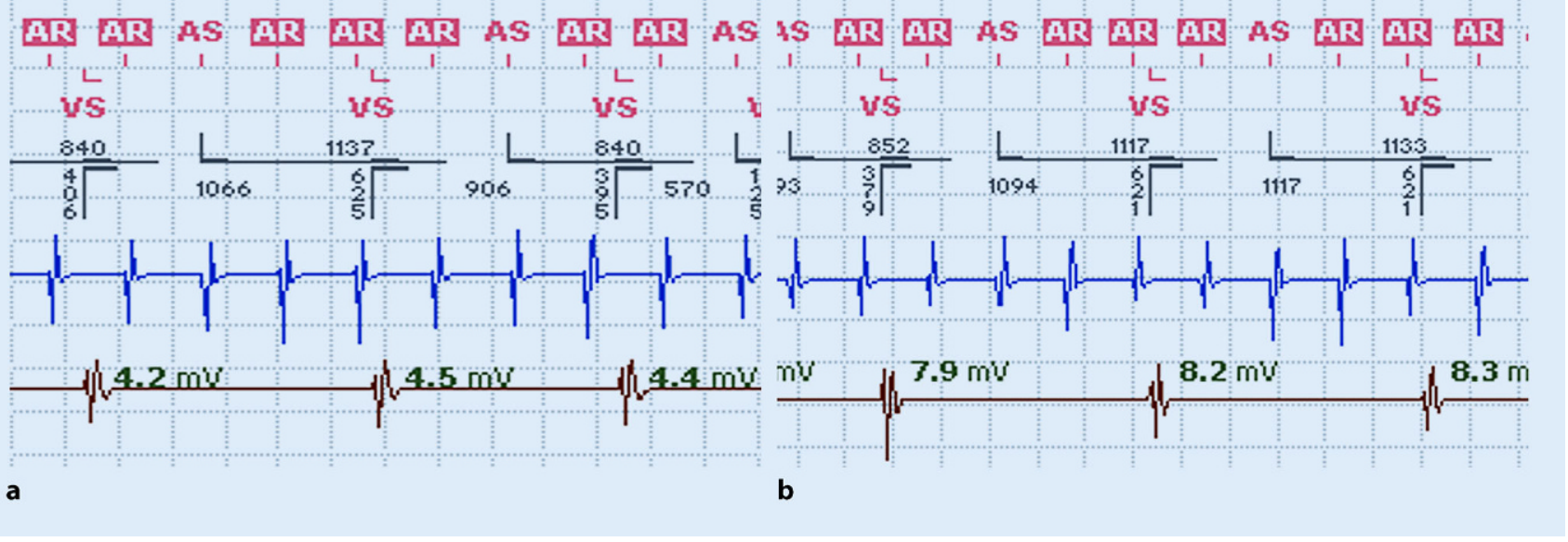

Fig. $7 \Delta$ a Right ventricular (RV) sensing with the low frequency attenuation (LFA) filter off in a patient with a replaced ICD system. $\mathbf{b}$ RV sensing with LFA Filter on
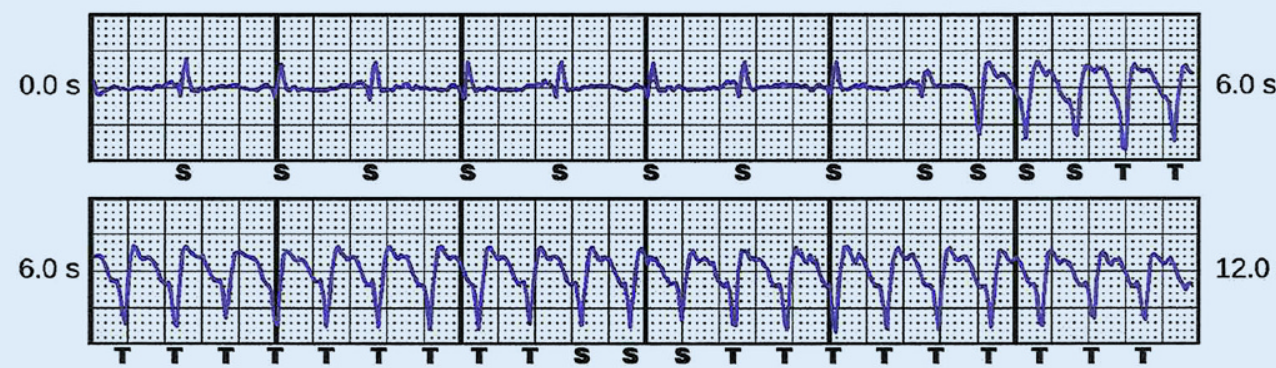

$12.0 \mathrm{~s}$

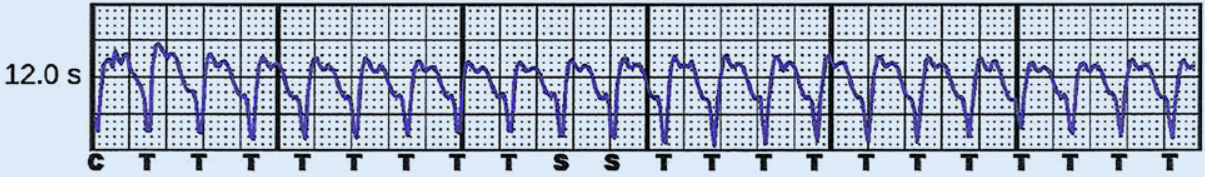

$18.0 \mathrm{~s}$

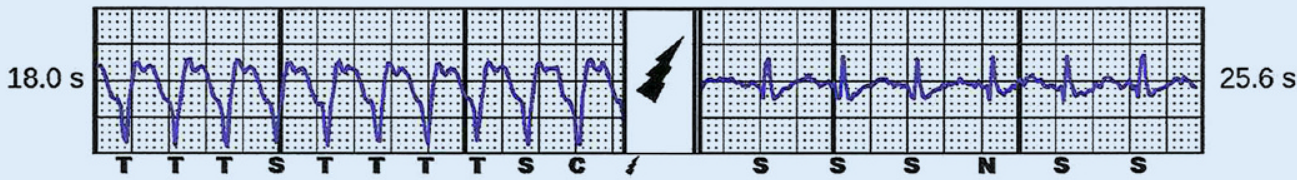

Fig. $8<$ Example of subcutaneous implantable cardioverter/defibrillator electrogram

the S-ICD system. It analyses the three sensing vectors and selects the one least likely to oversense. The complex is then compared with previous complexes [10]. However, if a patient develops new conduction abnormalities, it is important that the S-ICD should be reinterrogated immediately and templates updated to rule out oversensing [57].

\section{Insertable cardiac monitors}

ICMs are used to obtain ambulatory electrocardiograms (ECG) and detect subclinical AF as well as unexplained syncope and to find possible arrhythmic ori- gins of palpitations. The devices have been miniaturised since their first introduction and the original ICM is now about as obsolete as the memory stick it resembled. Devices are inserted near the left fourth intercostal space corresponding to the V2-V3 ECG lead location and an ECG tracing is measured between two electrodes at the ends [26]. Most present-day ICMs use automatic arrhythmia detection which is then confirmed by remote monitoring. Compared with pacemakers, ICM algorithms are more limited and based on R-R interval stability, although some advanced algorithms have added $\mathrm{P}$-wave detection once the
R-R variability exceeds the AF threshold, to improve specificity for AF [17].

The performance of ICMs in AF detection has been evaluated in comparison with 48-h Holter monitoring in a number of studies, which have reported high sensitivity (96-100\%) and high negative predictive values $(98 \%$ for the absence of AF in the XPECT trial [29]). But specificity has been less constantly impressive, ranging from 67 to $86 \%[7,18$, 29]. The rate of false positives for AF detection can be as high as $42 \%$ [7]. A randomised comparison in 2016 reported significantly higher rates of correct $\mathrm{AF}$ identification with pacemakers than with 


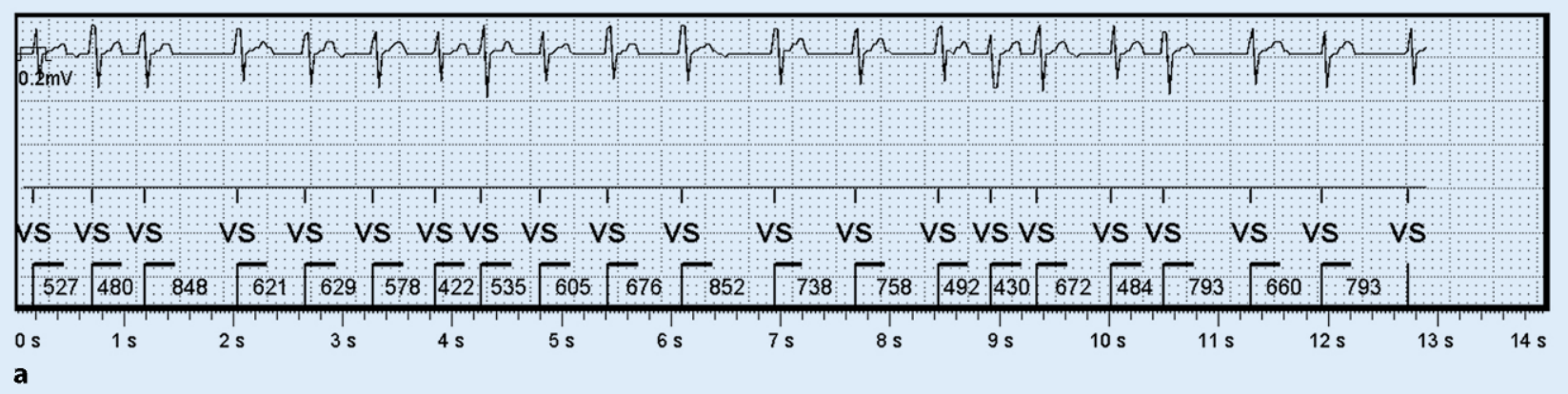

1:VEGM AutoGain $(14 \mathrm{~mm} / \mathrm{mV})$

2: Marker

Sweep speed: $25 \mathrm{~mm} / \mathrm{s}$
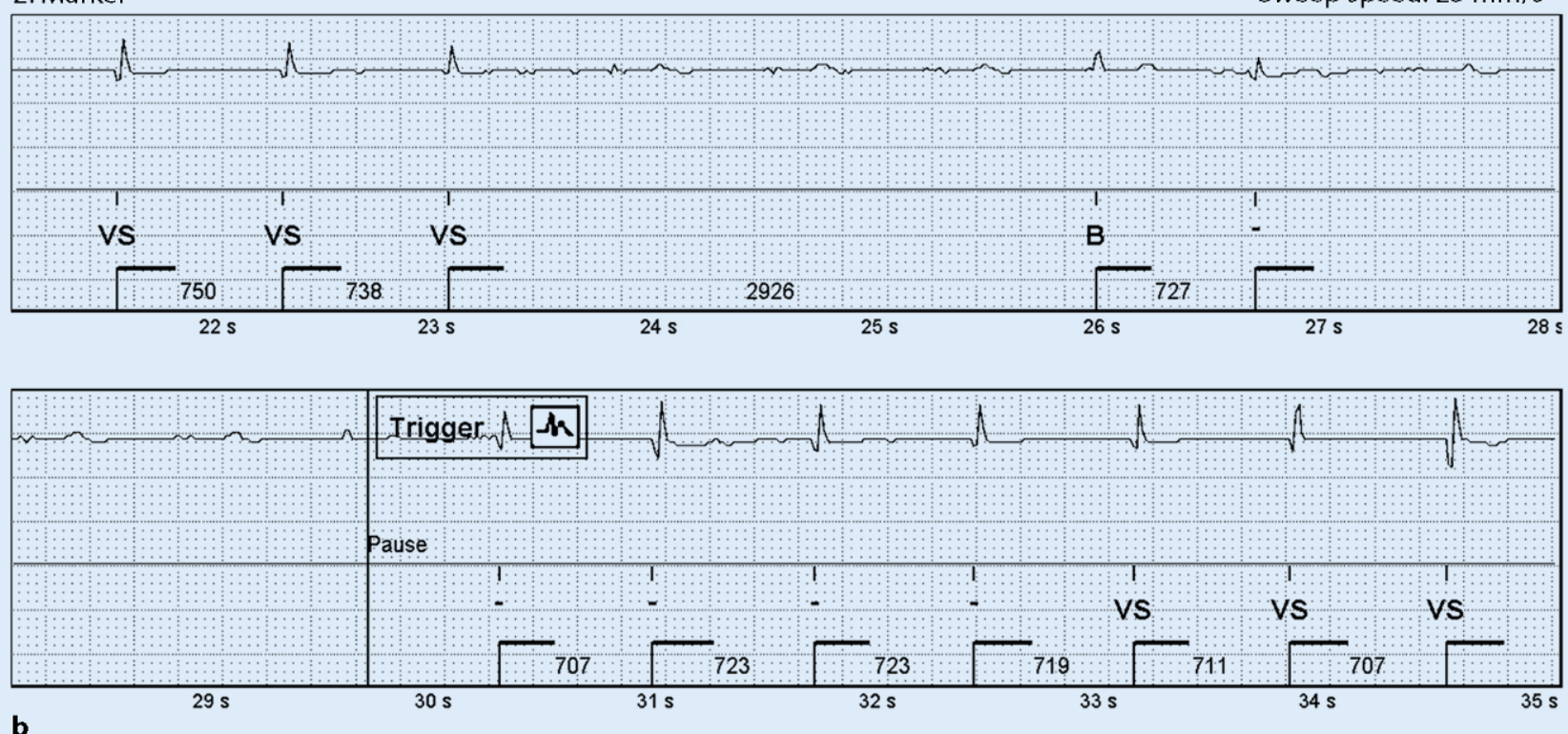

b

Fig. $9 \Delta$ a Example of atrial fibrillation on insertable cardiac monitor electrogram. b Incorrect detection due to undersensing. VEGM ventricular electrogram using a can to header vector

ICM (97\% vs $55 \%)$ as well as significantly greater sensitivity and specificity and PPV [50]. For risk assessment purposes, these differences may not be as important as the numbers imply. ICMs appear to perform similarly to pacemakers in assessing the total AF burden, with false-positive and false-negative episodes to some extent cancelling each other out in the total assessment $[7,50]$. For other arrhythmias, Maines et al. reported 20\% false bradycardia detection by ICM due to undersensing and 3\% false tachycardia detection due to oversensing [40].

The false positive arrhythmia alerts which drive the inaccurate diagnostic performance of ICM are mostly related to inadequate $\mathrm{R}$-wave sensing. As the ICM electrodes are positioned at some distance from the cardiac muscle, there is greater scope for interference and artefacts [6, 7, 47]. Typically, an R-wave sensing value of at least $0.3 \mathrm{mV}$ is targeted [21]. Undersensing due to a decrease in $\mathrm{R}$-wave amplitude is more common than oversensing and can lead to false diagnosis of bradycardia or pauses as well as false AF alerts [21]. Continual refinements to algorithms include enhanced noise rejection techniques to reduce inappropriate identification of arrhythmias, but at the cost of slightly reduced sensitivity and detection of appropriate arrhythmias [8]. Nonparasternal implant sites appear to be associated with more inadequate $\mathrm{R}$-wave sensing and false arrhythmia diagnoses than parasternal sites [21]. In contrast to S-ICDs, the orientation of the device may influence detection; the R-wave amplitude is known to change with changing patient postures and associated orientations of the heart [19]. Sudden reductions in amplitude may also lead to loss of signal detection by ICMs (• Fig. 9).

The main problem with ICMs remains the inability to obtain a clear and accurate signal during subcutaneous ECG monitoring, with a high frequency of artefacts leading to frequent non-diagnostic interrogations [17].

\section{Wearable defibrillators}

The wearable cardioverter defibrillator (WCD) received US Food and Drug Administration market approval and the European CE Mark in 2001. It is used in 


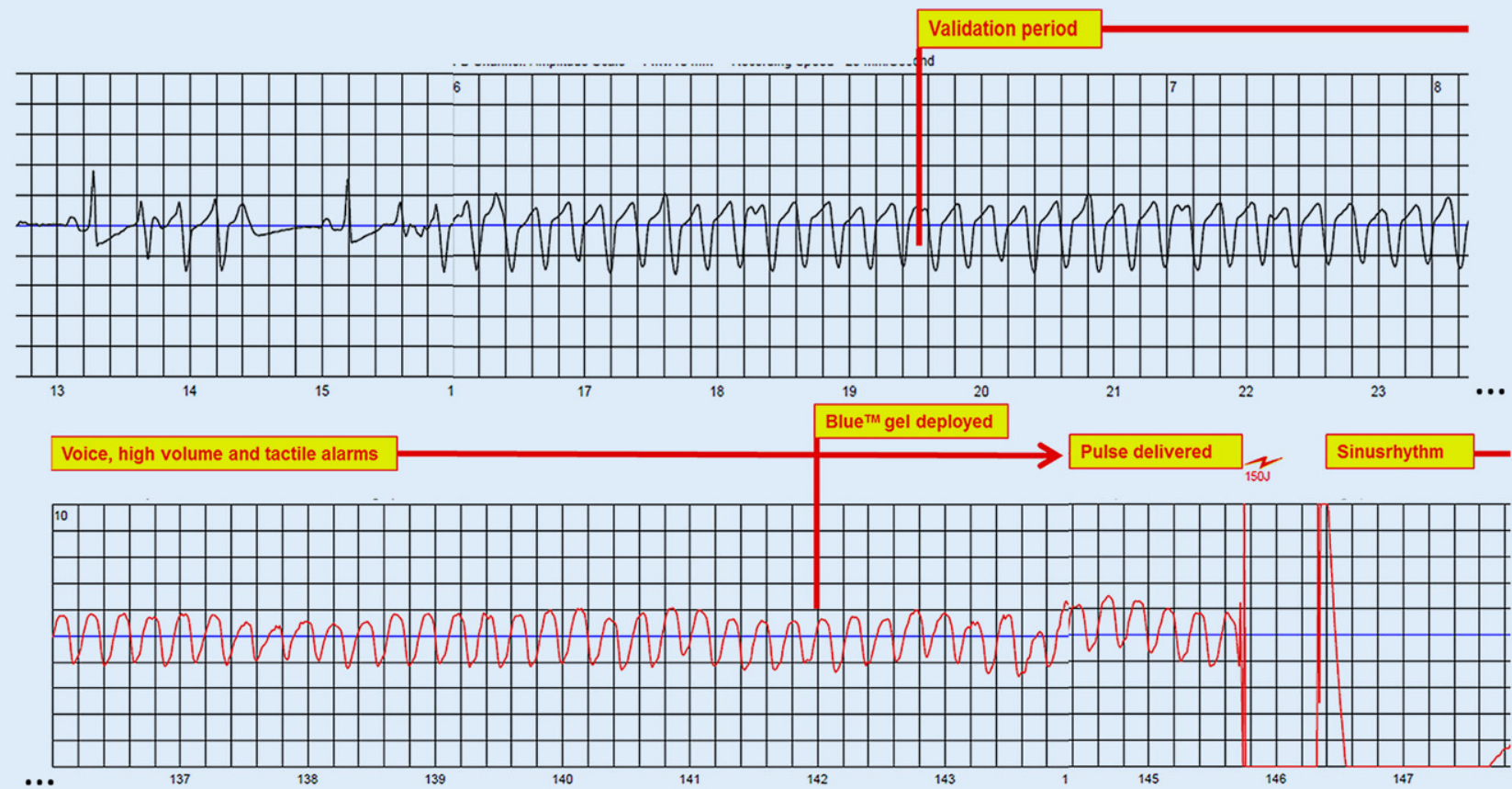

a

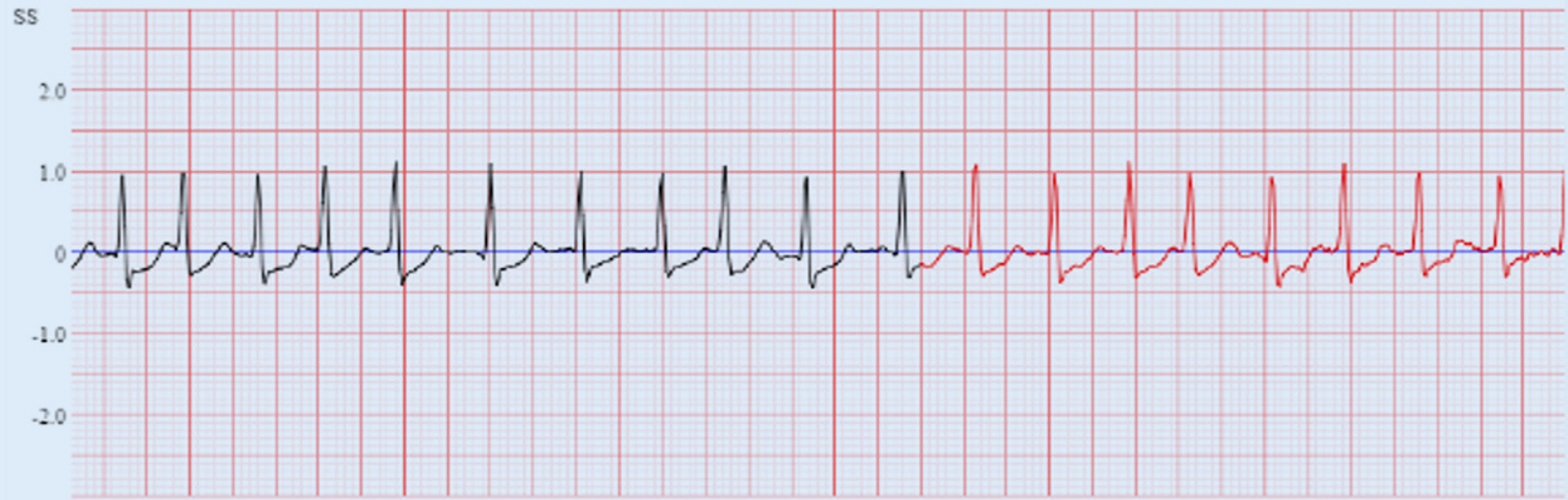

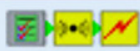

FB

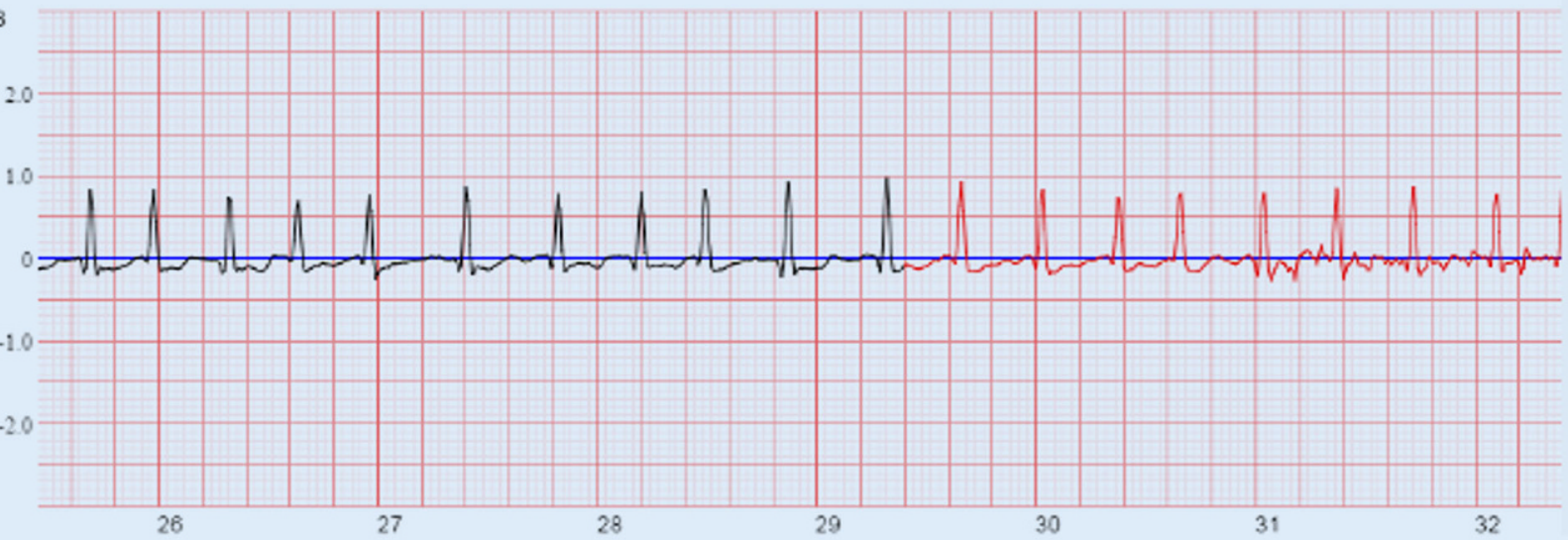

b

26

27

28

31

32

Fig. $10 \Delta$ Wearable defibrillator electrograms showing a ventricular tachycardia and $\mathbf{b}$ atrial fibrillation 


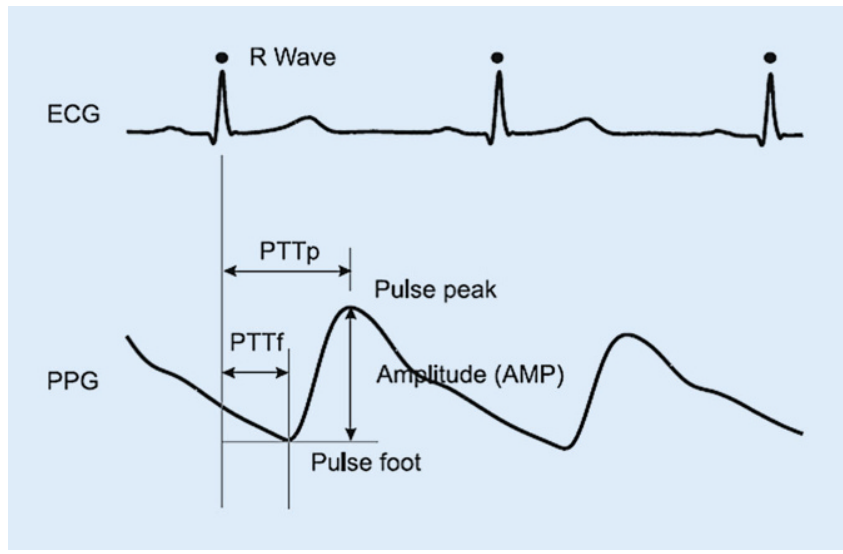

Fig. $11 \Delta$ The pulsatile (AC) component of the photoplethysmography signal and corresponding electrocardiogram. In actual use, the AC component is superimposed on the much larger quasi-DC component. PTTf beat-to-beat pulse transit time to the foot of the pulse, PTTp pulse transit time to the peak of the pulse. The pulse landmarks can be used to calculate the normalised pulse contour. From Allen [3], used with permission

patients at temporary high risk for ventricular arrhythmias, or those with evolving cardiac conditions who may need an ICD in future, but in whom in-hospital monitoring would be impracticable [60]. WCD use is recommended in current European Society of Cardiology (ESC) guidelines for the management of patients with ventricular arrhythmias and the prevention of sudden cardiac death [52].

The WCD is a vest which incorporates three defibrillation electrode pads (positioned for apex-to-posterior defibrillation), a defibrillation unit and four dry, nonadhesive ECG-sensing electrodes which provide continuous electrocardiographic monitoring of front-back and left-right site bipolar surface ECG leads $[16,23]$. The monitoring electrodes are placed circumferentially around the chest and pushed against it by tension from an elastic belt. Ventricular tachycardia and ventricular fibrillation are detected by an algorithm which uses ECG morphology analysis and programmable threshold heart rates, with a VF zone programmable between 120 and 250 beats/min, and a VT zone programmable between 120 beats/min and the VF detection rate (- Fig. 10). Suspected arrhythmias trigger an alarm during which the patient has the option to withhold treatment. This means that most treated ventricular arrhythmias occur in unconscious patients. Perhaps for the same reason, rates of inappropriate shocks are low $[31,46,55]$.

\section{Wearable monitors and consumer electronics}

Wearable devices equipped with monitors and algorithms to detect heart rate, ECG or other biorhythms are becoming alternatives to CIEDs when direct electrical stimulation of the heart is not necessary. A survey in 2018 showed that even among "elderly" people ( $>65$ years old) there was great interest in the future use of wearable devices to obtain various health benefits [33]. The pressure to reduce personal routine visits to healthcare providers in the wake of the coronavirus pandemic will probably act in wearable monitors' favour as it facilitates diagnosis and risk assessment without the use of face-to-face encounters.

The ability of smartwatches and wearable fitness trackers to detect irregularities in the heart rhythm is based on PPG. The process compares the amount of infrared light reflected back from the skin from a green-light emitting diode. As haemoglobin absorbs some of the original light, changes in capillary volume with each pulsation will be indicated by changes in the intensity of the reflected light (- Fig. 11; [3]). The pulsatile component of the PPG waveform is often called the "AC" component and is superimposed on a large "quasi-DC" com- ponent that relates to the tissues and to the average blood volume. Several relevant variables can be extrapolated from the analysis of the PPG waveform morphology and its features, including heart rate and rhythm, blood pressure and arterial stiffness, cardiac output, arterial ageing, endothelial function, microvascular blood flow, autonomic function or respiratory rate $[3,13]$.

The technology has the great advantage of being non-invasive and easy to incorporate into accessories which do not need to be primarily medical but would be worn by a patient on a daily basis. This may make them serious alternatives, e.g. to ICMs for AF monitoring. The challenges are the need for sufficient capillary blood flow to generate a reliable signal, which means the analysis works less well in cases of low blood pressure or vasoconstriction. The accuracy may be affected by patient movement as well as by beats, and it is also not immune to light conditions or the ambient temperature.

Wearable devices use different proprietary algorithms to determine heart rate from the PPG signals. Today there is little information on how these algorithms work, which gives the devices a "black box" characteristic. Moreover, PPG cannot identify atrial activity (P waves) and thus are not suitable for atrial arrhythmia monitoring unless combined with ECG for confirmation (- Fig. 12). Devices have been developed which carry PPG and ECG systems, but ECGs are designed to be recorded while subjects are inactive and PPG signals may be confounded by movement [14]. A comparison in 2020 of four common wearable PPG-using devices found all to be poor at detecting short episodes of supraventricular tachycardias, particularly for episodes shorter than $60 \mathrm{~s}$ [58].

Large-scale studies on AF identification have shown the strengths and weaknesses of wearables. In the Apple Heart Study [49] patients with device notifications of AF were provided with an ECG patch for confirmatory analysis. Although $84 \%$ of notifications of an irregular pulse were concordant with $\mathrm{AF}$ on subsequent ECG patch readings, the diagnostic yield was only $34 \%$. In the WATCH AF study the diagnostic accu- 


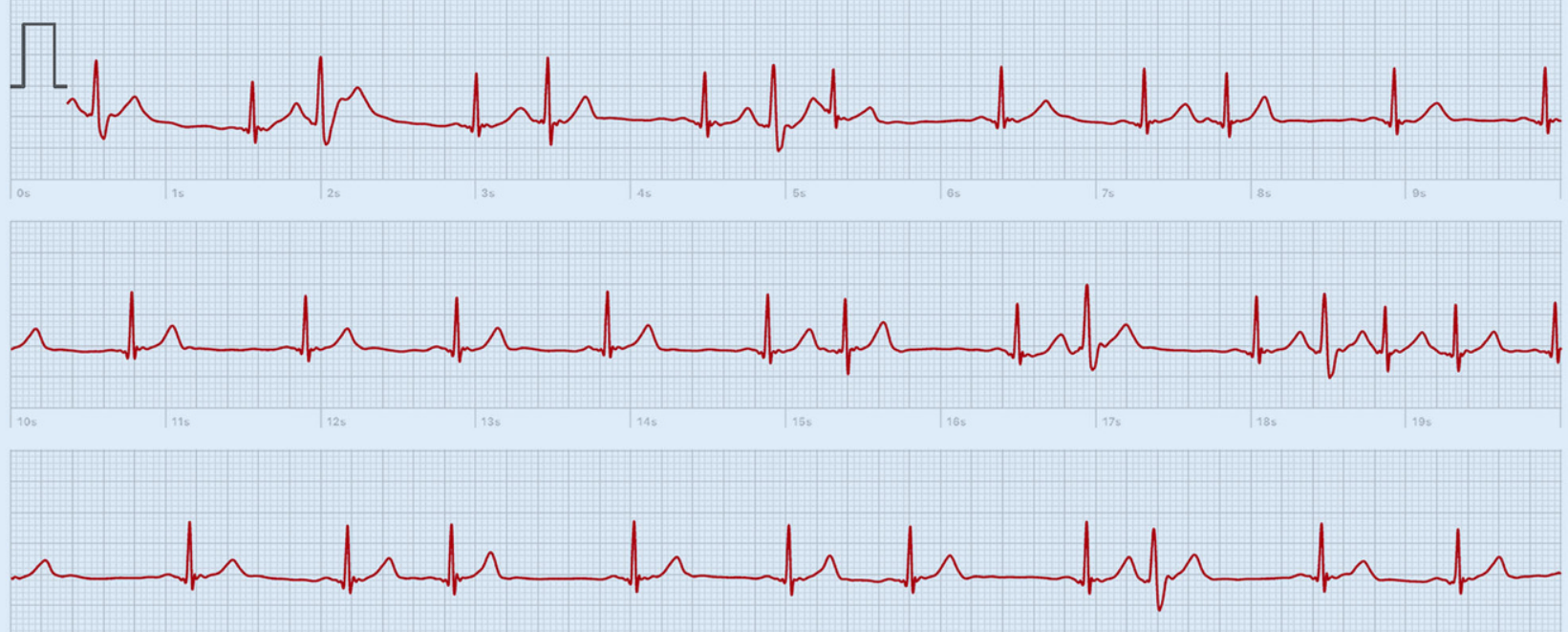

$25 \mathrm{~mm} / \mathrm{s}, 10 \mathrm{~mm} / \mathrm{mV}$, Ableitung I, $512 \mathrm{~Hz}$, iOS 13.5.1, watchOS 6.2.6, Watch4,4 -

a
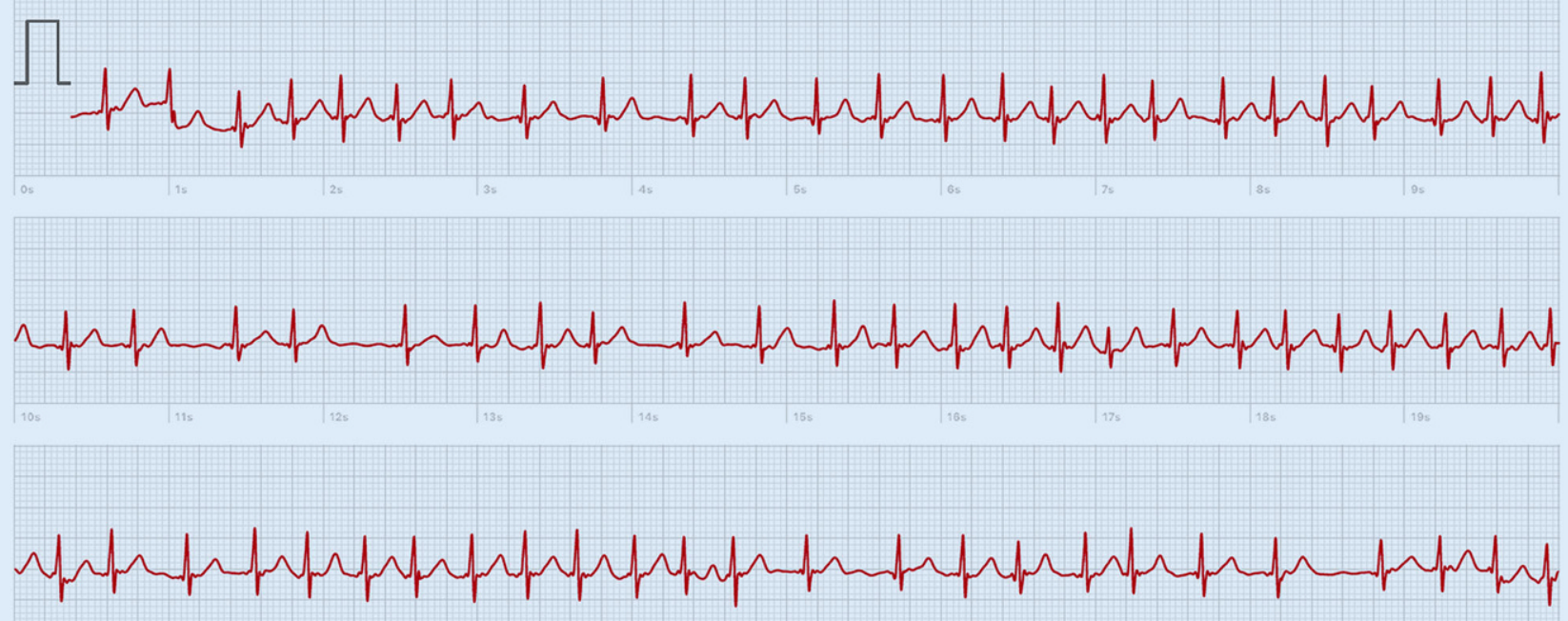

$25 \mathrm{~mm} / \mathrm{s}, 10 \mathrm{~mm} / \mathrm{mV}$, Ableitung I, $512 \mathrm{~Hz}$, iOS 13.5.1, watchos 5.2, Watch 4,4

\section{b}

Fig. $12 \Delta$ Apple watch tracings showing a extrasystole and $\mathbf{b}$ atrial fibrillation

racy was high but $22 \%$ of the datasets were not suitable for PPG analysis [22]. None of the trials could assess sensitivity and the rate of failed detections is unknown.

Similar problems were reported with the Kardia Band for which 34\% of readings were interpreted as unclassified by the automated algorithm [12]. In the Huawei Heart Study, "possible AF" episodes identified by the device were adjudicated by health providers, but
$38 \%$ of patients with notification of $\mathrm{AF}$ were not assessed for validation and less than half of the notified patients entered follow-up [28].

In general, a lower population prevalence will reduce the PPV, given the smaller proportion of true positives relative to false positives. Accordingly, the PPV of wearable devices will be reduced with an increased use of wearable monitors in the general population. The studies discussed above were huge:
187,912 subjects in the Huawei Heart and 419,297 participants in the Apple Heart studies, respectively. In these megatrials, the AF yield in an unselected population was very small: 0.2 and $0.5 \%$, respectively $[28,49]$. This is not surprising given that most smartwatch wearers are young and relatively healthy-in the Huawei study the average age overall was 36 years compared with 54 years in those $(0.23 \%)$ that received a notification of suspected AF. This indicates 
a need to select target populations to reduce the data tsunami generated by devices, as well as for automated filtering of transmitted information. It may also be relevant to note that most wearables are used by men [28, 49] and women may need to be actively targeted.

\section{Outlook}

The development of new cardiac devices and therapies is continuing at a rapid pace. What has changed in more recent years is the contribution of Big Data and AI, which has moved monitoring into the public domain, with uncertain consequences. Wearable and other mobile communication technologies have become a powerful driver of change in healthcare by influencing the expectations of patients (as well as of many healthy individuals). However, wearable monitors bring new risks together with the new opportunities. Continuous monitoring is likely to identify occasional arrhythmias in the healthiest of hearts and the challenge is for the general public and physicians alike to know what information to take seriously and what to dismiss. To monitor a huge population of the "worried well" may flood doctors' offices with low-risk patients that have received an alert from their watch, to the detriment of healthcare infrastructure and to the care of patients that need intervention [36].

The application of AI to healthcare is complicated by the "black-box" nature of deep learning and by the "move fast and break things" business model of Big Tech. The introduction of bug-ridden products, which are then refined by incremental updates as data on performance and shortcomings become available, may be acceptable in consumer electronics and possibly risk assessment. But where users' health and even lives may be at stake, devices will need to perform reliably from the start. Without a clear understanding of machine learning, even among experts, it will be very difficult to deal with confounding factors.

On the upside, given the immense amount of data, machine learning algorithms can be expected to improve enormously in quality and may feed back into improved CIEDs to improve detection and therapy delivery if applied in dialogue with available knowledge.

The coronavirus pandemic will supercharge changes in healthcare provision which were already underway. Health authorities globally are trying to increase access to telemedicine and patients are becoming increasingly comfortable with attending virtual consulting sessions rather than travelling to treatment centres and exposing themselves to the risk of infections [5]. Monitoring will grow in importance in this shifting landscape.

\section{Corresponding address}

Prof. Dr. Johannes Sperzel
Heartcenter, Electrophys-
iology/Device therapies,
Kerckhoff-Klinik GmbH
Benekestr. 2-8, 61231 Bad
Nauheim, Germany
j.sperzel@kerckhoff-klinik.de

\section{Compliance with ethical guidelines}

Conflict of interest. J.Sperzel received speaker fees and institutional research grants from Abbott, Biotronik, Boston Scientific, Impulse Dynamics, Microport and Zoll. C.W. Hamm and A. Hain declare that they have no competing interests.

For this article no studies with human participants or animals were performed by any of the authors. All studies performed were in accordance with the ethical standards indicated in each case.

\section{References}

1. Alasti M, Machado C, Kotschet E, Alison J (2019) Inappropriate shock due to myopotential oversensing in a patient with subcutaneous implantable cardioverter-defibrillator. Heart Lung Circ 28:e88-e90. https://doi.org/10.1016/j.hlc. 2018.08.030

2. Al-Khatib SM, Stevenson WG, Ackerman MJ et al (2018) 2017 AHA/ACC/HRS guideline for management of patients with ventricular arrhythmias and the prevention of sudden cardiac death. J Am Coll Cardiol 72:e91-e220. https://doi. org/10.1016/j.jacc.2017.10.054

3. Allen J (2007) Photoplethysmography and its application in clinical physiological measurement. Physiol Meas 28:R1-R39. https://doi.org/10.1088/ 0967-3334/28/3/R01

4. Auricchio A, Schloss EJ, Kurita T et al (2015) Low inappropriate shock rates in patients with single- and dual/triple-chamber implantable cardioverter-defibrillators using a novel suite of detection algorithms: PainFree SST trial primary results. Heart Rhythm 12:926-936. https://doi. org/10.1016/j.hrthm.2015.01.017

5. Bagchi C (2020) Telehealth in the era of COVID19. https://www.eiu.com/n/telehealth-in-theera-of-covid-19/. Accessed 10 June 2020

6. Bisignani A, De Bonis S, Mancuso L et al (2018) Implantable loop recorder in clinical practice. J Arrhythmia 35:25-32. https://doi.org/10.1002/ joa3.12142

7. Bisignani A, De Bonis S, Mancuso L et al (2020) Are implantable cardiac monitors reliable tools for cardiac arrhythmias detection? An intrapatient comparison with permanent pacemakers. J Electrocardiol 59:147-150. https://doi.org/10. 1016/j.jelectrocard.2020.02.014

8. Brignole M, Moya A, de Lange FJ et al (2018) 2018 ESC Guidelines for the diagnosis and management of syncope. Eur Heart J 39:1883-1948. https://doi. org/10.1093/eurheartj/ehy037

9. Briongos-Figuero S, Sánchez A, Pérez ML et al (2019) Single-brand dual-chamber discriminators to prevent inappropriate shocks in patients implanted with prophylactic implantable cardioverter defibrillators: a propensity-weighted comparison of single- and dual-chamber devices. J Interv Card Electrophysiol 54:267-275. https:// doi.org/10.1007/s10840-018-0494-0

10. Brisben AJ, Burke MC, Knight BP et al (2015) A new algorithm to reduce inappropriate therapy in the S-ICD system: a new algorithm to reduce inappropriate therapy. J Cardiovasc Electrophysiol 26:417-423. https://doi.org/10.1111/jce.12612

11. van den Bruck J-H, Sultan A, Plenge T et al (2019) Incidence of myopotential induction in subcutaneous implantable cardioverter-defibrillator patients: Is the oversensing issue really solved? Heart Rhythm 16:1523-1530. https://doi.org/10. 1016/j.hrthm.2019.04.044

12. Bumgarner JM, Lambert CT, Hussein AA et al (2018) Smartwatch algorithm for automated detection of atrial fibrillation. J Am Coll Cardiol 71:2381-2388. https://doi.org/10.1016/j.jacc.2018.03.003

13. Castaneda D, Esparza A, Ghamari M et al (2018) A review on wearable photoplethysmography sensors and their potential future applications in health care. Int J Biosens Bioelectron 4:195-202. https://doi.org/10.15406/ijbsbe.2018.04.00125

14. Chen E, Jiang J, Su R et al (2020) A new smart wristband equipped with an artificial intelligence algorithm to detect atrial fibrillation. Heart Rhythm 17:847-853. https://doi.org/10.1016/j. hrthm.2020.01.034

15. Chinitz L, Ritter P, Khelae SKet al (2018) Accelerometer-based atrioventricular synchronous pacing with a ventricular leadless pacemaker: results from the micra atrioventricular feasibility studies. Heart Rhythm 15:1363-1371. https://doi.org/10.1016/j. hrthm.2018.05.004

16. Chung MK, Szymkiewicz SJ, Shao M et al (2010) Aggregate national experience with the wearable cardioverter-defibrillator. J Am Coll Cardiol 56:194-203. https://doi.org/10.1016/j.jacc.2010. 04.016

17. Ciconte G, Giacopelli D, Pappone C (2017) The role of implantable cardiac monitors in atrial fibrillation management. J Atr Fibrillation. https://doi.org/10. 4022/jafib.1590

18. Ciconte G, Saviano M, Giannelli L et al (2017) Atrial fibrillation detection using a novel three-vector cardiac implantable monitor: the atrial fibrillation detect study. EP Eur 19:1101-1108. https://doi. org/10.1093/europace/euw181

19. van Dam P, van Groeningen C, Houben RPM, Hampton DR (2009) Improving sensing and 
detection performance in subcutaneous monitors. J Electrocardiol 42:580-583. https://doi.org/10. 1016/j.jelectrocard.2009.06.024

20. Daubert JP, Zareba W, Cannom DS et al (2008) Inappropriate implantable cardioverter-defibrillator shocks in MADITII. J Am Coll Cardiol 51:1357-1365. https://doi.org/10.1016/j.jacc.2007.09.073

21. De Coster M, Demolder A, De Meyer V et al (2020) Diagnostic accuracy of R-wave detection by insertable cardiac monitors. Pacing Clin Electrophysiol. https://doi.org/10.1111/pace. 13912

22. Dörr M, Nohturfft V, Brasier N et al (2019) The WATCH AF trial: SmartWATCHes for detection of atrial fibrillation. JACC Clin Electrophysiol 5:199-208. https://doi.org/10.1016/j.jacep.2018. 10.006

23. Epstein AE, Abraham WT, Bianco NR et al (2013) Wearable cardioverter-defibrillator use in patients perceived to be at high risk early post-myocardial infarction. JAm Coll Cardiol 62:2000-2007. https:// doi.org/10.1016/j.jacc.2013.05.086

24. Friedman PA (2006) Dual-chamber versus single-chamber detection enhancements for Implantable defibrillator rhythm diagnosis: the detect supraventricular tachycardia study. Circulation 113:2871-2879. https://doi.org/10.1161/ CIRCULATIONAHA.105.594531

25. Fung JWH, Sperzel J, Yu CM et al (2009) Multicenter clinical experience with an atrial lead designed to minimize far-field R-wave sensing. Europace 11:618-624. https://doi.org/10.1093/europace/ eup078

26. Giancaterino S, Lupercio F, Nishimura M, Hsu JC (2018) Current and future use of insertable cardiac monitors. JACC Clin Electrophysiol 4:1383-1396. https://doi.org/10.1016/j.jacep.2018.06.001

27. Gold MR, Theuns DA, Knight BP et al (2012) Headto-head comparison of arrhythmia discrimination performance of subcutaneous and transvenous ICD arrhythmia detection algorithms: the START study. J Cardiovasc Electrophysiol 23:359-366. https://doi.org/10.1111/j.1540-8167.2011.02199. $x$

28. Guo Y, Wang H, Zhang H et al (2019) Mobile photoplethysmographic technology to detect atrial fibrillation. J Am Coll Cardiol 74:2365-2375. https://doi.org/10.1016/j.jacc.2019.08.019

29. Hindricks G, Pokushalov E, Urban L et al (2010) Performance of a new leadless Implantable cardiac monitor in detecting and quantifying atrial fibrillation results of the XPECT trial. Circ Arrhythm Electrophysiol 3:141-147. https://doi.org/10. 1161/CIRCEP.109.877852

30. Israel CW, Gascon D, Nowak B et al (2000) Diagnostic value of stored electrograms in singlelead VDD systems. Pacing Clin Electrophysiol 23:1801-1803. https://doi.org/10.1111/j.15408159.2000.tb07023.x

31. Kao AC, Krause SW, Handa R et al (2012) Wearable defibrillator use in heart failure (WIF): results of a prospective registry. BMC Cardiovasc Disord 12:123. https://doi.org/10.1186/1471-2261-12123

32. Kaufman ES, Israel CW, Nair GM et al (2012) Positive predictive value of device-detected atrial highrate episodes at different rates and durations: An analysis from ASSERT. Heart Rhythm 9:1241-1246. https://doi.org/10.1016/j.hrthm.2012.03.017

33. Kekade S, Hseieh C-H, Islam Md M et al (2018) The usefulness and actual use of wearable devices among the elderly population. Comput Methods Programs Biomed 153:137-159. https://doi.org/ 10.1016/j.cmpb.2017.10.008
34. Kolb C, Wille B, Maurer D et al (2006) Management of far-field $R$ wave sensing for the avoidance of inappropriate mode switch in dual chamber pacemakers: results of the FFS-test study. J Cardiovasc Electrophysiol 17:992-997. https:// doi.org/10.1111/j.1540-8167.2006.00545.x

35. Koplan BA, Kaplan AJ, Weiner S et al (2009) Heart failure decompensation and all-cause mortality in relation to percent biventricular pacing in patients with heart failure. J Am Coll Cardiol 53:355-360. https://doi.org/10.1016/j.jacc.2008.09.043

36. Kowey PR, Robinson VM (2019) The evolution of the one-armed bandit. J Am Coll Cardiol 74:2376-2378. https://doi.org/10.1016/j.jacc 2019.09.019

37. Lambiase PD, Barr C, Theuns DAMJ et al (2014) Worldwide experience with a totally subcutaneous implantable defibrillator: early results from the EFFORTLESSS-ICD registry. Eur Heart J35:1657-1665. https://doi.org/10.1093/eurheartj/ehu112

38. Lau C-P, Leung S-K, Tse H-F, Barold SS (2002) Automatic mode switching of implantable pacemakers: I. Principles of instrumentation clinical, and hemodynamic considerations. Pacing Clin Electrophysiol 25:967-983. https://doi.org/ 10.1046/j.1460-9592.2002.00967.x

39. Mahajan R, Perera T, Elliott AD et al (2018) Subclinical device-detected atrial fibrillation and stroke risk: a systematic review and meta-analysis Eur Heart J 39:1407-1415. https://doi.org/10. 1093/eurheartj/ehx731

40. Maines M, Zorzi A, Tomasi G et al (2018) Clinical impact, safety, and accuracy of the remotely monitored implantable loop recorder Medtronic Reveal LINQTM. EP Eur 20:1050-1057. https://doi. org/10.1093/europace/eux187

41. Martin DT, Bersohn MM, Waldo AL et al (2015) Randomized trial of atrial arrhythmia monitoring to guide anticoagulation in patients with implanted defibrillator and cardiac resynchronization devices. Eur Heart J 36:1660-1668. https://doi.org/ 10.1093/eurheartj/ehv115

42. Morschhäuser D, Fischer W, Jakob M (2019) Praxis der Herzschrittmacher-Nachsorge: Grundlagen, Funktionen, Kontrolle, Optimierung, Troubleshooting https://doi.org/10.1007/978-3662-57828-5

43. Nazer B, Dale Z, Carrassa G et al (2020) Appropriate and inappropriate shocks in hypertrophic cardiomyopathy patients with subcutaneous implantable cardioverter-defibrillators: an international multicenter study. Heart Rhythm. https:// doi.org/10.1016/j.hrthm.2020.02.008

44. Nölker G, Mayer J, Boldt L-H et al (2016) Performance of an implantable cardiac monitor to detect atrial fibrillation: results of the DETECT AF study: DETECT AF study results. J Cardiovasc Electrophysiol 27:1403-1410. https://doi.org/10. 1111/jce.13089

45. Olde Nordkamp LRA, Brouwer TF, Barr C et al (2015) Inappropriate shocks in the subcutaneous ICD: Incidence, predictors and management. Int J Cardiol 195:126-133. https://doi.org/10.1016/j. ijcard.2015.05.135

46. Olgin JE, Pletcher MJ, Vittinghoff E et al (2018) Wearable cardioverter-defibrillator after myocardial infarction. N Engl J Med 379:1205-1215. https://doi.org/10.1056/NEJMoa1800781

47. Padmanabhan D, Kancharla K, El-Harasis MA et al (2019) Diagnostic and therapeutic value of implantable loop recorder: a tertiary care center experience. Pacing Clin Electrophysiol 42:38-45 https://doi.org/10.1111/pace.13533
48. Passman RS, Weinberg $K M$, Freher $M$ et al (2004) Accuracy of mode switch algorithms for detection of atrial tachyarrhythmias. J Cardiovasc Electrophysiol 15:773-777. https://doi.org/10. 1046/j.1540-8167.2004.03537.x

49. Perez MV, Mahaffey KW, Hedlin Hetal (2019) Largescale assessment of a sSmartwatch to identify atrial fibrillation. N Engl J Med 381:1909-1917. https:// doi.org/10.1056/NEJMoa1901183

50. Podd SJ, Sugihara C, Furniss SS, Sulke N (2016) Are implantable cardiac monitors the 'gold standard' for atrial fibrillation detection? A prospective randomized trial comparing atrial fibrillation monitoring using implantable cardiac monitors and DDDRP permanent pacemakers in post atrial fibrillation ablation patients. Europace 18:1000-1005. https://doi.org/10.1093/europace/euv367

51. Poole JE, Johnson GW, Hellkamp AS et al (2008) Prognostic importance of defibrillator shocks in patients with heart failure. $\mathrm{N}$ Engl J Med 359:1009-1017

52. Priori SG, Blomström-Lundqvist C, Mazzanti A et al (2015) 2015 ESC guidelines for the management of patients with ventricular arrhythmias and the prevention of sudden cardiac death: the task force for the management of patients with ventricular arrhythmias and the prevention of sudden cardiac death of the European Society of Cardiology (ESC). Endorsed by: association for European Paediatric and Congenital Cardiology (AEPC). Eur Heart J 36:2793-2867. https://doi.org/10.1093/ eurheartj/ehv316

53. Purerfellner $H$, Gillis AM, Holbrook R, Hettrick DA (2004) Accuracy of atrial tachyarrhythmia detection in Implantable devices with arrhythmia therapies. Pacing Clin Electrophysiol 27:983-992. https://doi.org/10.1111/j.1540-8159.2004.00569. $x$

54. Ricci RP (2018) Cardiac pacing: basic concepts. In: Boriani G (ed) ESC CardioMed. Oxford University Press, Oxford, pp 1974-1978

55. Rosenkaimer SL, El-Battrawy I, Dreher TC et al (2020) The wearable cardioverter-defibrillator: experience in 153 patients and a long-term follow-up. J Clin Med. https://doi.org/10.3390/ jcm9030893

56. Rudic B, Tülümen $E$, Fastenrath $F$ et al (2020) Incidence, mechanisms, and clinical impact of inappropriate shocks in patients with a subcutaneous defibrillator. Europace 22:761-768. https:// doi.org/10.1093/europace/euaa026

57. Salgado BC, CoramR, Mandrola J, GopinathannairR (2018) Inappropriate shock from delayed T-wave oversensing by a subcutaneous implantable cardioverter-defibrillator after septal myectomy for hypertrophic cardiomyopathy. HeartRhythm Case Rep 4:408-411. https://doi.org/10.1016/j. hrcr.2018.06.004

58. Sequeira N, D'Souza D, Angaran P et al (2020) Common wearable devices demonstrate variable accuracy in measuring heart rate during supraventricular tachycardia. Heart Rhythm 17:854-859. https://doi.org/10.1016/j.hrthm.2020.02.018

59. Solari D, Bertero E, Miceli R et al (2017) Methods, accuracy and clinical implications of atrial fibrillation detection by cardiac implantable electronic devices. Int J Cardiol 236:262-269. https://doi.org/10.1016/j.ijcard.2016.12.189

60. Sperzel J (2016) Value of the Wearable Cardioverter Defibrillator (WCD) as a bridging-therapy before Implantation of a Cardioverter Defibrillator (ICD). J Atr Fibrillation. https://doi.org/10.4022/jafib. 1247 
61. Steinwender C, Khelae SK, Garweg C et al (2020) Atrioventricular synchronous pacing using a leadless ventricular pacemaker. JACC Clin Electrophysiol 6:94-106. https://doi.org/10.1016/ j.jacep.2019.10.017

62. Sweeney MO (2003) Adverse effect of ventricular pacing on heartfailure and atrial fibrillation among patients with normal baseline QRS duration in a clinical trial of pacemaker therapy for sinus node dysfunction. Circulation 107:2932-2937. https:// doi.org/10.1161/01.CIR.0000072769.17295.B1

63. Sweeney MO, Sherfesee L, DeGroot PJ et al (2010) Differences in effects of electrical therapy type for ventricular arrhythmias on mortality in implantable cardioverter-defibrillator patients. Heart Rhythm 7:353-360. https://doi.org/10. 1016/j.hrthm.2009.11.027

64. Swerdlow $C D$, Asirvatham SJ, Ellenbogen KA, Friedman PA (2015) Troubleshooting implantable cardioverter-defibrillator sensing problems II. Circ Arrhythm Electrophysiol 8:212-220. https://doi. org/10.1161/CIRCEP.114.002514

65. Swerdlow CD, Brown ML, Bordachar P (2017) Sensing and detection with cardiac Implantable electronic devices. In: Clinical cardiac pacing, defibrillation and resynchronization therapy. Elsevier, Amsterdam, pp 114-167

66. Theuns DAMJ, Rivero-Ayerza M, Boersma E, Jordaens $L$ (2008) Prevention of inappropriate therapy in implantable defibrillators: a metaanalysis of clinical trials comparing single-chamber and dual-chamber arrhythmia discrimination algorithms. Int J Cardiol 125:352-357. https://doi. org/10.1016/j.ijcard.2007.02.041

67. Weretka S, Michaelsen J, Becker R et al (2003) Ventricular oversensing:: a study of 101 patients implanted with dual chamber defibrillators and two different lead systems. Pacing Clin Electrophysiol 26:65-70. https://doi.org/10.1046/ j.1460-9592.2003.00152.x

68. Wilkoff BL, Auricchio A, Brugada J et al (2008) HRS/EHRA expert consensus on the monitoring of cardiovascular Implantable electronic devices (CIEDs): description of techniques, indications, personnel, frequency and ethical considerations. Europace 10:707-725

69. Wilson DG, Leventigiannis G, Barr C, Morgan JM (2016) ECG predictors of T wave oversensing in subcutaneous implantable cardioverter defibrillators. Int J Cardiol 220:27-31. https://doi.org/10. 1016/j.jijcard.2016.06.128 